\title{
Isolation of Staphylococcus aureus from sputum in cystic fibrosis
}

\author{
P. D. SPARHAM, D. I. LOBBAN, AND D. C. E. SPELLER
}

From the Bacteriology Department, Bristol Royal Hospital for Sick Children, Bristol BS2 8BJ, UK

SUMMARY The success in the isolation of Staphylococcus aureus of different methods of sputum processing was investigated in 60 specimens collected from 14 patients with cystic fibrosis during a seven-month period. Fifty specimens $(83 \%)$ from 11 patients yielded Staph. aureus by one or more methods. Direct plating of purulent portions of sputum on to media designed for general use in respiratory infections gave unsatisfactory results $(35 \%$ yield of Staph. aureus). Some increase in isolations was obtained with preliminary liquefaction of sputum; but the best results were given by the addition of a medium selective for staphylococci (mannitol salt agar, BBL) or by initial sonication of sputum (each $83 \%$ yield). Seven of the 11 strains of Staph. aureus were thymidine-dependent and otherwise atypical in laboratory characteristics; these were isolated from patients who had received co-trimoxazole.

In the respiratory infections of cystic fibrosis, Haemophilus influenzae, Staphylococcus aureus, and Pseudomonas aeruginosa have been recognised as the important pathogens (May et al., 1972; Mearns et al., 1972), and detection of their presence in sputum is essential for satisfactory antibiotic treatment. There is usually no difficulty with $P$ s. aeruginosa except that some strains require prolonged incubation before they produce recognisable colonies. Isolation of $\boldsymbol{H}$. influenzae can be increased by the addition of a selective medium (Baber, 1969), which is used for all sputum specimens in this laboratory.

It was recognised, however, that the Staph. aureus strains present in sputa from these patients were not always fully defined in our laboratory reports. Typical staphylococci might be seen in a Gram film but not isolated or recognised in cultures. Some isolates failed to grow in antibiotic sensitivity tests. There appeared to be three reasons for this: the staphylococci were readily overgrown by other bacteria; their colonial appearances were often uncharacteristic; and some isolates were nutritionally deficient (Williams, 1977).

This investigation was undertaken to improve the methods for detection and characterisation of Staph. aureus. Selective and indicator media for staphylococci were compared, and the most discriminating was selected. The effect of sonication on Ps. aeruginosa and Staph. aureus was studied. The

Received for publication 6 March 1978 success of the laboratory's routine methods for sputum culture was compared with the results of the introduction of the selective medium, of two methods of preliminary liquefaction of sputum, and of sonication of sputum.

\section{Methods}

\section{COMPARISON OF SELECTIVE MEDIA}

The following freshly prepared media were studied: milk agar (Christie and Keogh, 1940), salt milk agar (Cruickshank et al., 1975), polymyxin B agar (as in Cruickshank et al., 1975, except that the polymyxin was added finally to the medium when it had been autoclaved), tellurite egg yolk agar (Alder et al., 1962), and two brands of mannitol salt agar (MSA)Oxoid and BBL.

The bacteria tested on these media were clinical isolates of Staph. aureus - both nutritionally normal strains and thymidine-dependent (thy $\left.{ }^{-}\right)$strains isolated from patients with cystic fibrosis-Staph. epidermidis, Ps. aeruginosa, viridans streptococci, and Neisseria catarrhalis. Single colonies from pure cultures were inoculated into $10-\mathrm{ml}$ amounts of heart infusion broth (HIB), which were incubated for 20 hours at $37^{\circ} \mathrm{C}$. Viable counts were estimated by the method of Miles and Misra (Miles et al., 1938) with culture in triplicate on all selective media and on $5 \%$ horse blood agar. Colonies were counted at approx. 20 hours and at approx. 40 hours, because growth of staphylococci was slow on MSA and on tellurite egg yolk agar. Viable counts on the selective 
media were expressed as percentage of the counts on the non-selective blood agar.

\section{SONICATION}

An MSE 150-watt ultrasonic disintegrator operating at $20 \mathrm{KH}_{3}$, with a $3 / 8$ inch titanium probe (McIntosh and Munro, 1971), was used. Volumes of $10 \mathrm{ml}$ were treated in round-bottomed plastic containers, sealed with membrane, and immersed in an ice-bath.

Cultures (20-hour) of Ps. aeruginosa and Staph. aureus in $10 \mathrm{ml}$ of HIB with $0.1 \%$ agar, and mixtures of the two, were subjected to sonication for periods of 0-5 minutes, and viable counts were performed, in triplicate, on Pseudocel Agar (BBL), a selective medium for $P$ s. aeruginosa containing cetrimide, and on MSA (BBL).

COMPARISON OF METHODS FOR CULTURE OF SPUTUM

\section{Sputum specimens}

Sixty specimens from 14 patients with cystic fibrosis were received in the laboratory during seven months. The patients, who were aged 3 to 16 years, were selected as having frequent outpatient attendances. The specimens were cultured by routine laboratory methods, with preliminary liquefaction and sonication, and on the selective medium.

\section{Routine method for examination of sputum}

Purulent portions were taken with a bacteriological loop, used to prepare a Gram-stained smear, and inoculated on to $5 \%$ horse blood agar, 'chocolate agar' with bacitracin 10 units per ml (Baber, 1969), and MacConkey's bile-salt lactose agar. The plates were incubated for 20 hours at $37^{\circ} \mathrm{C}$, the first two in air with $5 \%$ carbon dioxide, and the last in air. Plates yielding no growth were re-incubated for a further day.

\section{Selective medium}

Mannitol salt agar (BBL) was similarly inoculated and incubated in air.

\section{Liquefaction}

Sputa were treated by standard methods with pancreatin (Rawlins, 1953) and $N$-acetyl-1-cysteine (Airbron, BDH) (Mead and Woodhams, 1964).

Sonication (Williams, 1977)

Sputa in 10-ml volumes, or measured volumes made up to $10 \mathrm{ml}$ with sterile distilled water, were treated for two minutes.

Liquefied and sonicated sputa were plated on the routine and the selective media and incubated as above. In addition, viable counts of Staph. aureus were estimated on MSA.

\section{BACTERIAL IDENTIFICATION}

Staph. aureus was identified by the slide-clumping factor test; negative strains were subjected to the tube coagulase test. Ps. aeruginosa was identified by the methods described by Phillips (1969).

\section{THYMIDINE DEPENDENCE}

Thy - strains of Staph. aureus were detected by their failure to grow on media with low thymidine/ thymine content, such as DST agar (Oxoid) with lysed blood. They showed satellitism around thymidine-impregnated discs on basal media, and were able to grow normally when $32 \mathrm{mg}$ per litre thymidine was added to such media.

\section{Results}

The recovery of the various bacteria on different selective and indicator media is shown in Table 1. Milk agar and polymyxin B agar were unsatisfactory in allowing the growth of Ps. aeruginosa and of upper respiratory tract commensals. Salt milk agar was satisfactorily inhibitory but also partially suppressed the staphylococci, which were difficult to recognise on this medium. Tellurite egg-yolk agar required up to five days' incubation for recognisable growth of all Staph. aureus strains, and permitted some growth of $P s$. aeruginosa. MSA inhibited $P s$. aeruginosa and commensals satisfactorily, allowed

Table 1 Growth of laboratory cultures on selective media

\begin{tabular}{|c|c|c|c|c|c|c|}
\hline \multirow[t]{2}{*}{ Medium } & \multicolumn{6}{|c|}{ Percentqge recovery (compared with blood agar) } \\
\hline & Staph. aureus & Staph. aureus (thy-) & Staph. epidermidis & Ps. aeruginosa & $\begin{array}{l}\text { Viridans } \\
\text { streptococci }\end{array}$ & N. catarrhalis \\
\hline $\begin{array}{l}\text { Blood agar } \\
\text { Milk agar } \\
\text { Salt milk agar } \\
\text { Polymyxin B agar } \\
\text { Tellurite egg yolk agar } \\
\text { Mannitol salt agar (Oxoid) } \\
\text { Mannitol salt agar (BBL) }\end{array}$ & $\begin{array}{r}100 \\
92 \\
85 \\
80 \\
95 \\
100 \\
98\end{array}$ & $\begin{array}{r}100 \\
93 \\
87 \\
76 \\
92 \\
0 \\
100\end{array}$ & $\begin{array}{r}100 \\
85 \\
85 \\
79 \\
90 \\
92 \\
100\end{array}$ & $\begin{array}{r}100 \\
100 \\
0 \\
33 \\
40 \\
0 \\
0\end{array}$ & $\begin{array}{r}100 \\
<1 \\
0 \\
55 \\
<1 \\
0 \\
0\end{array}$ & $\begin{array}{r}100 \\
88 \\
0 \\
63 \\
0 \\
0 \\
0\end{array}$ \\
\hline
\end{tabular}




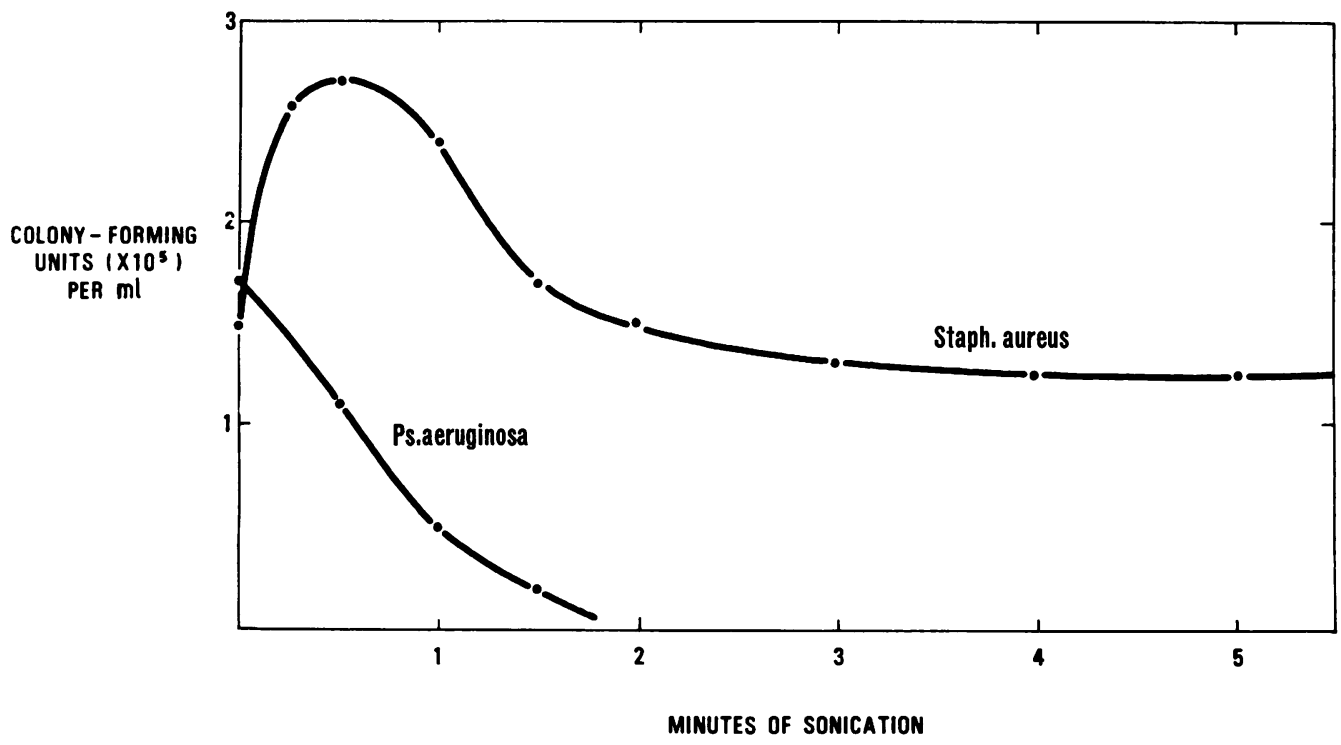

Fig. 1 Effect of sonication on cultures of Staph. aureus and Ps. aeruginosa

growth of staphylococci, and permitted presumptive distinction between Staph. aureus and Staph. epidermidis. Oxoid MSA, however, did not support the growth of thy-Staph. aureus. BBL MSA, which gave $100 \%$ recovery of these strains, was therefore selected for further use.

The effect of sonication on cultures of Staph. aureus and Ps. aeruginosa is illustrated in Figure 1. $P$ s. aeruginosa was almost completely destroyed at two minutes, while Staph. aureus showed little decline from the original count at five minutes. The increase in colony-forming units during the first minute of sonication is presumably due to the breaking up of clumps of staphylococci (Huhtanen, 1966). This differential effect of sonication on a sputum specimen containing both bacteria is shown in Figure 2.

The total isolations of Staph. aureus and Ps.

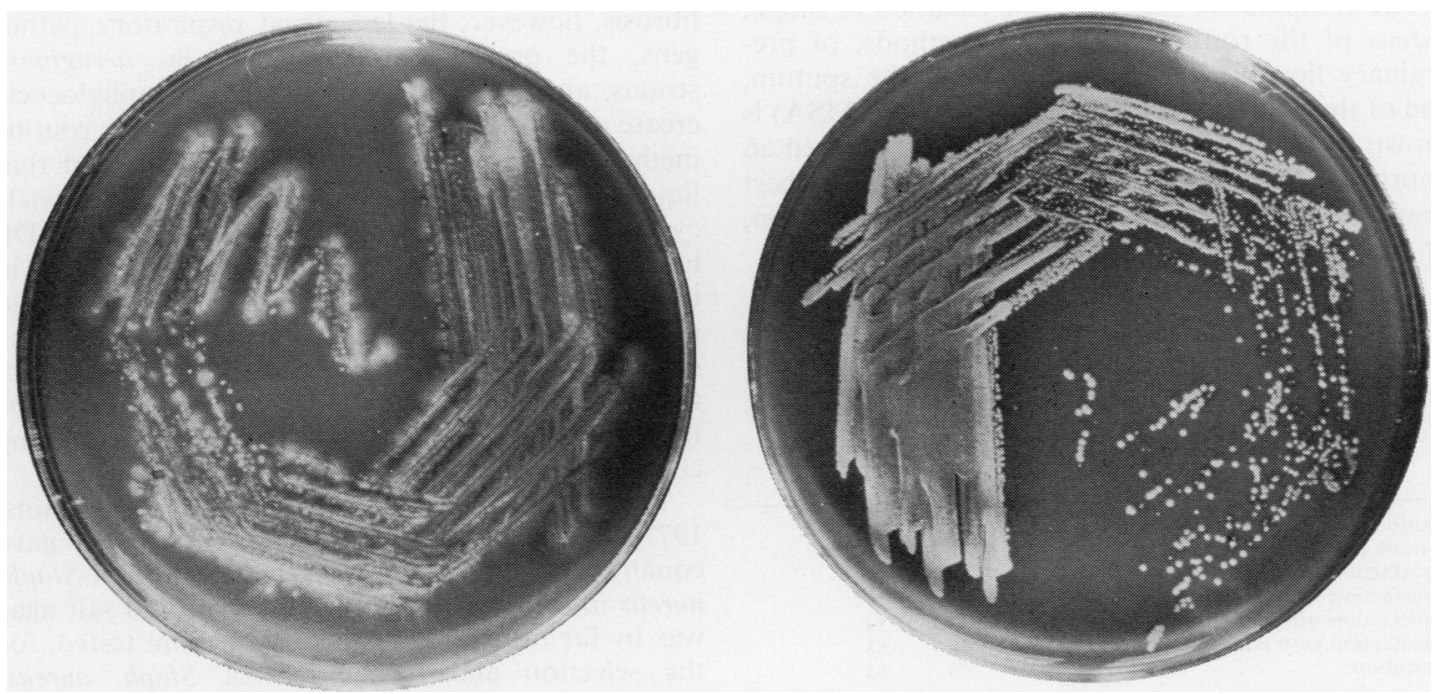

Fig. 2 Sputum specimen containing both Ps. aeruginosa and Staph. aureus plated on blood agar before (left) and after (right) sonication for 2 minutes 
aeruginosa from the 60 sputum samples surveyed are given in Table 2. The viable counts of Staph. aureus (in the 50 specimens from which it was isolated by one or more method) after the two methods of liquefaction and after sonication are compared in Table 3. The numbers of instances in which each method yielded the highest viable count, those in which it yielded the highest count by a clear margin, and those in which no Staph. aureus was isolated, are given.

Table 2 Recovery of pathogens from sputa (all methods)

\begin{tabular}{lll}
\hline Bacterium & No. of specimens & Per cent \\
\hline Staph. aureus & 50 & 83 \\
Ps. aeruginosa & 38 & 63 \\
Both & 30 & 50 \\
Neither & 2 & 3 \\
\hline
\end{tabular}

Total number of specimens: 60

Table 3 Recovery of Staph. aureus from sputa after liquefaction and after sonication

\begin{tabular}{llcl}
\hline Method & $\begin{array}{l}\text { Number of specimens for which the } \\
\text { viable count was }\end{array}$ & Failure \\
\cline { 2 - 4 } & Highest or equal highest & Clear highest \\
\hline Pancreatin & 26 & 11 & 0 \\
$N$-acetyl-1-cysteine & 8 & 2 & 3 \\
Sonication & 37 & 21 & 0 \\
\hline
\end{tabular}

Total number of specimens: 50

The comparative success in the isolation of Staph. aureus of the routine laboratory methods, of preliminary liquefaction or sonication of the sputum, and of the addition of the selective medium (MSA) is shown in Table 4. All the methods tested showed an improvement on the routine method, but the best result ( $83 \%$ positive) was obtained with sonication, or with the addition of MSA.

Table 4 Isolation of Staph. aureus from sputaoverall success of methods

\begin{tabular}{lll}
\hline Method & \multicolumn{2}{l}{$\begin{array}{l}\text { Specimens yielding } \\
\text { Staph. aureus }\end{array}$} \\
\cline { 2 - 3 } & No. & Per cent \\
\hline Routine & 21 & 35 \\
Routine plus MSA & 50 & 83 \\
Liquefaction with $N$-acetyl-1-cysteine & 30 & 50 \\
Liquefaction with $N$-acetyl-1-cysteine + MSA & 47 & 78 \\
Liquefaction with pancreatin & 32 & 53 \\
Liquefaction with pancreatin + MSA & 50 & 83 \\
Sonication & 50 & 83 \\
& & \\
\hline
\end{tabular}

Total number of specimens: 60
Of the 14 patients, 11 yielded Staph. aureus during the seven months of the investigation. Seven of the 11 strains were found to be thymidinedependent. They were frequently bizarre in colonial form (Fig. 3) (Williams, 1977), and clumping factor negative but tube coagulase positive. They would not grow on DST agar, with or without lysed blood, nor on Oxoid MSA, nor on blood agar even when as little as $2.5 \%$ lysis of the blood had occurred. They produced small, often rough, colonies on BBL MSA. All seven patients who yielded thy- ${ }^{-}$Staph. aureus had previously been treated with co-trimoxazole. Thy ${ }^{-}$clones could be produced in the laboratory from nutritionally normal Staph. aureus strains isolated from other patients, by growth in proteosepeptone broth containing $10 \mathrm{mg}$ per litre trimethoprim.

\section{Discussion}

The routine methods used in this hospital group for the examination of sputum do not include the preliminary liquefaction of the specimens that has been adopted by most laboratories. A local survey of methods (unpublished) revealed that nine of 14 bacteriology laboratories in the South Western Region used some liquefaction method, while the others relied on the direct plating of purulent material. Wilkinson et al. (1977) showed that preliminary liquefaction did not have any advantage over direct plating in the examination of sputa from patients with clinical evidence of postoperative respiratory infection, provided that the selective medium for $\boldsymbol{H}$. influenzae was included. In cystic fibrosis, however, the less usual respiratory pathogens, the prevalence of mucoid Ps. aeruginosa strains, and the characteristics of the staphylococci create special difficulcies. It is clear that our routine method will not do for these specimens, and that liquefaction of sputum, by pancreatin or $N$-acetyl-1 cysteine, only partially solves the problems. Dilutions of the liquefied sputum were not cultured in this investigation, but it is unlikely that this would greatly improve the recovery of staphylococci. The method exerts no selective effect, and in almost all the specimens in this study there were at least 100 times more pseudomonas than staphylococci (colony counts).

The introduction either of sonication (Williams, 1977) or of a selective medium, however, gave equally great improvement in the isolation of Staph. aureus in the present study. BBL mannitol salt agar was by far the most satisfactory medium tested, for the selection and recognition of Staph. aureus, including thy- variants, and has now been added to our routine methods for specimens from patients 


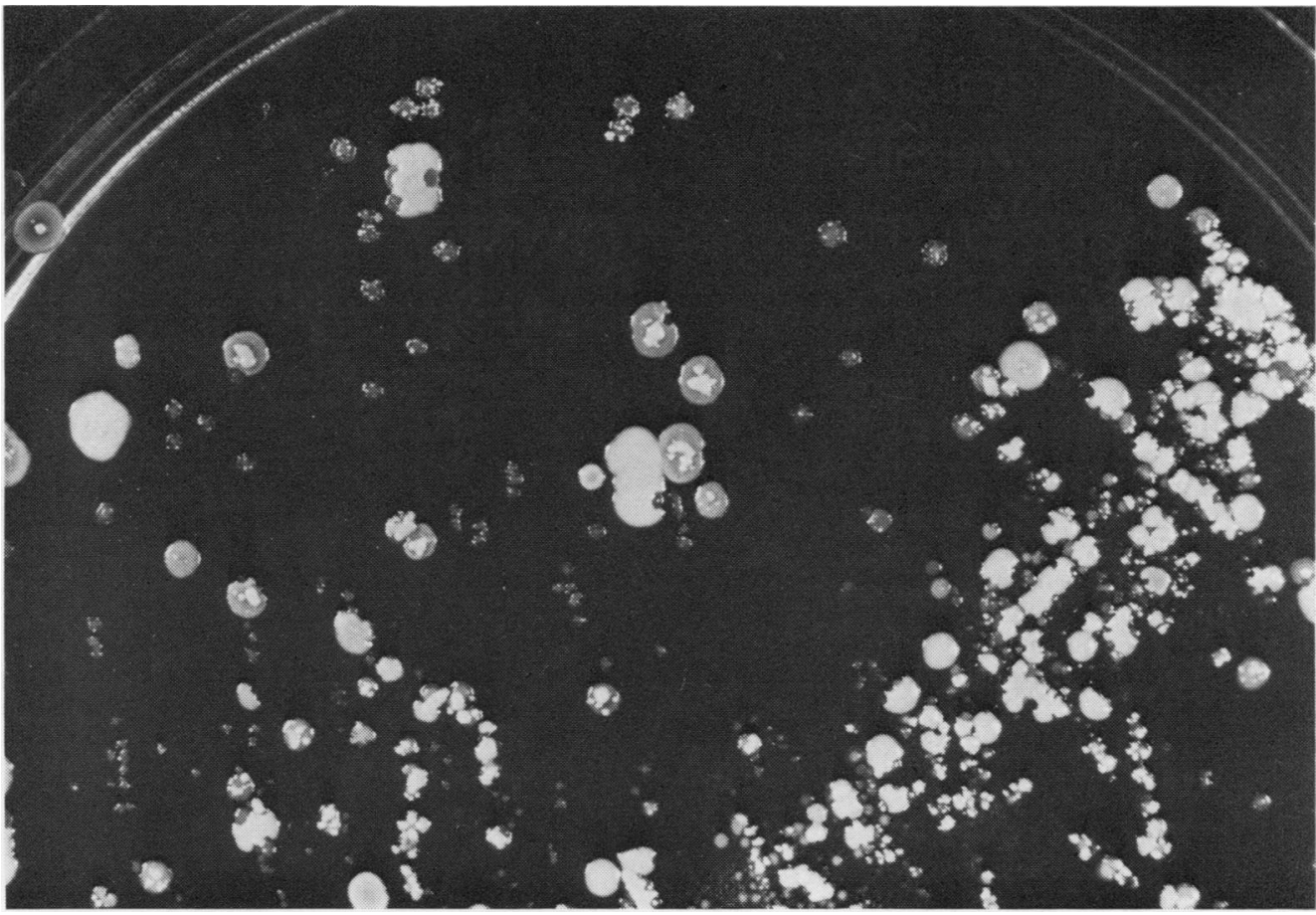

Fig. 3 Pure culture of Staph. aureus from sputum, on blood agar, showing varied colonial forms $\times($ approx. 6)

with cystic fibrosis. This addition requires no new apparatus or procedures and is cheap in terms of materials and time. It does require two days' incubation, and the numbers of staphylococcal colonies isolated may be reduced.

Sonication, although it yielded the highest counts of Staph. aureus in the majority of cases, and produced an easily handled liquid specimen, is not recommended for routine use. It requires expensive apparatus, and as it destroys other important bacteria it has to be a separate additional technique. There are problems of overheating of samples, the production of aerosols, the need to sterilise the probe between runs, and distress to the operator from noise.

It must be emphasised that the successful use of any of these methods depends ultimately on the recognition of Staph. aureus when it is grown. Strains that have peculiar colonial forms, are clumping factor negative, or fail to grow on sensitivity testing media may be discarded by the unwary.

The use of co-trimoxazole is valuable in cystic fibrosis, especially in the treatment of $H$. influenzae infections in the presence of Staph. aureus, and longterm administration may prevent frequent relapse. The emergence of thy- Staph. aureus, however, must be expected. The pathogenicity of these strains has not been definitely established, but conditions in the respiratory tract should favour their normal growth (George and Healing, 1977).

In conclusion, it may be said that satisfactory recognition of Staph. aureus in the sputum of patients with cystic fibrosis requires either preliminary sonication or the use of a selective medium and, in either case, diligent and critical examination of the cultures.

We are grateful to the medical and nursing staff of the Bristol Children's Hospital for their interest and cooperation in these investigations, and to Dr R. Fraser Williams, Cystic Fibrosis Research Laboratory, Booth Hall Children's Hospital, Manchester, M9 2AA, for his continued advice and encouragement.

\section{References}

Alder, V. G., Gillespie, W. A., and Waller, L. J. (1962). The use of tellurite-egg yolk medium for the isolation and identification of staphylococci in hospitals. Journal of Applied Bacteriology, 25, 436-440.

Baber, K. G. (1969). A selective medium for the isolation of haemophilus from sputum. Journal of Medical Laboratory Technology, 26, 391-396. 
Christie, R., and Keogh, E. V. (1940). Physiological and serological characteristics of staphylococci of human origin. Journal of Pathology and Bacteriology, 51, 189197.

Cruickshank, R., Duguid, J. P., Marmion, B. P., and Swain, R. H. A. (1975). Medical Microbiology, 12th edition, vol. 2. Churchill Livingstone, Edinburgh and London.

George, R. H., and Healing, D. E. (1977). Thymidinerequiring Haemophilus influenzae and Staphylococcus aureus (Letter). Lancet, 2, 1081.

Huhtanen, C. N. (1966). Effect of ultrasound on disaggregation of milk bacteria. Journal of Dairy Science, 49, 1008-1010.

McIntosh, A. F., and Munro, R. F. (1971). Ultrasonic treatment of microorganisms. Process Biochemistry, 6, 22-23, 27.

May, J. R., Herrick, N. C., and Thompson, D. (1972). Bacterial infection in cystic fibrosis. Archives of Disease in Childhood, 47, 908-913.

Mead, G. R., and Woodhams, A. W. (1964). N-acetyl-1cysteine as liquefying agent in the bacteriological examination of sputum. Tubercle, 45, 370-373.

Mearns, M. B., Hunt, G. H., and Rushworth, R. (1972).
Bacterial flora of respiratory tract in patients with cystic fibrosis, 1950-1971. Archives of Disease in Childhood, 57, 902-907.

Miles, A. A., Misra, S. S., and Irwin, J. O. (1938). The estimation of the bactericidal power of the blood. Journal of Hygiene, 38, 732-749.

Phillips, I. (1969). Identification of Pseudomonas aeruginosa in the clinical laboratory. Journal of Medical Microbiology, 2, 9-16.

Rawlins, G. A. (1953). Liquefaction of sputum for bacteriological examination. Lancet, 2, 538-539.

Wilkinson, P. J., Ball, A. J., Doran, J. Gillespie, W. A., and Orton, V. S. (1977). Routine laboratory assessment of postoperative chest infection: a prospective study. Journal of Clinical Pathology, 30, 417-420.

Williams, R. F. (1977). Infection of the respiratory tract in cystic fibrosis. In A Symposium on Cystic Fibrosis, edited by R. F. Williams, pp. 20-27. North Western Regional Health Authority.

Requests for reprints to: Professor D. C. E. Speller, University Department of Bacteriology, Bristol Royal Infirmary, Marlborough Street, Bristol, BS2 8HW, UK 